\title{
UMA PROPOSTA TEÓRICO-METODOLÓGICA PARA SUBSIDIAR A FACILITAÇÃO DE GRUPOS REFLEXIVOS E DE APOIO AO LUTO
}

\author{
A THEORETICAL-METHODOLOGICAL PROPOSAL TO SUPPORT \\ THE FACILITATION OF REFLECTIVE GROUPS AND SUPPORT FOR MOURNING
}

IVÂNIA JANN LUNA

Universidade Federal de Santa Catarina,

Florianópolis, SC, Brasil
Recebido em 13/07/2020 Aprovado em 27/11/2020
RESUMO: No presente artigo tenho como objetivo apresentar os fundamentos teóricos e os princípios metodológicos dos grupos reflexivos e de apoio ao luto (GRAL) com base na prática grupal realizada no âmbito de um serviço-escola de Psicologia. Destacam-se como relevantes os conceitos e procedimentos da metodologia de grupos reflexivos de gênero do Instituto Noos, da perspectiva construcionista social do luto, os princípios terapêuticos grupais e a postura ética no cuidado ao luto. Com base nestes aspectos conceituais, apresentam-se os objetivos e os princípios metodológicos do GRAL quanto ao seu modo de constituição, dispositivos para a sua realização e avaliação. 0 GRAL constitui uma proposta de construção de diálogos colaborativos, reflexivos e de apoio às pessoas no seu processo de enlutamento, de se engajar consigo próprio e com os outros, por meio da construção de empatia, sociabilidade e narrativas pessoais quanto à necessidade e direito ao luto público.

Palavras-chave: Luto; Grupos reflexivos; Construcionismo social; Narrativas.

ABSTRACT: This article aims to describe the theoretical foundations and methodological principles of reflective and grieving support groups (GRAL) based on group practice carried out within the scope of Psychology school service. The concepts and and procedures of the methodology of reflective groups of gender of the Noos Institute, the social constructionist perspective on mourning, group therapeutic principles and ethical care in mourning stand out as relevant. Based on these conceptual aspects, GRAL's objectives and methodological principles are presented in terms of its constitution, devices for its realization and evaluation. GRAL is a proposal to build collaborative, reflective and supportive dialogues for people in their grieving process, to engage with themselves and with others, through the construction of empathy, sociability and personal narratives about the need and right to public mourning.

Keywords: Mourning; Reflexive groups; Social constructionism; Narratives.

RESUMEN: Este artículo tiene como objetivo describir los fundamentos teóricos y los principios metodológicos de los grupos de apoyo reflexivos y de duelo (GRAL) basados en la práctica grupal realizada dentro del alcance del servicio de Psicología. Los conceptos y procedimientos de la metodología de grupos reflexivos de género del Instituto Noos, de la perspectiva construccionista social sobre el duelo, los principios terapéuticos grupales y la atención ética en el duelo se destacan como relevantes. A partir de estos aspectos conceptuales, se presentan los objetivos y principios metodológicos del GRAL en términos de su constitución, dispositivos para su realización y evaluación. GRAL es una propuesta para construir diálogos colaborativos, reflexivos y de apoyo a las personas en su proceso de duelo, para comprometerse consigo mismos y con los demás, a través de la construcción de empatía, sociabilidad y narrativas personales sobre la necesidad y el derecho al duelo público.

Palabras clave: Luto; Grupos reflexivos; Construcionismo social; Narrativas. 


\section{INTRODUÇÃO}

Oluto é uma vivência esperada frente à perda de uma pessoa ou objeto significativo. Por sua vez, é vivido e expressado de forma singular, tendo em vista os sentimentos de perda e os costumes fúnebres, crenças religiosas e dispositivos psicológicos e sociais a que acessa a pessoa enlutada ou o seu grupo de referência identitária. $\mathrm{Na}$ atualidade, o protagonismo público do enlutado envolve acionar recursos simbólicos que, segundo Walter (2000), possibilitam manter a individualidade e privacidade na vivência de uma perda. Destacam-se, nesse sentido, a realização de rituais coletivos e personalizados de luto, a busca por conhecimentos psicológicos sobre o processo de luto, bem como o uso de técnicas produzidas por profissionais especialistas do luto, sobretudo quando o enlutado acessa propostas e serviços formais de cuidado ao luto.

Nesse sentido, Gamino (2009) assinala como uma premissa fundamental a questão ética na tomada de decisão quando se está diante de situações e conflitos relacionados a cuidados em fim de vida ou de pessoas em situação de vulnerabilidade, pelo grau de sofrimento vivido ou por apresentar algum risco de invalidação social de sua dor no contexto dos relacionamentos sociais. Para este autor, isso significa a adoção de uma posição pluralista e sensível quanto às preferências e tradições de cada enlutado, bem como o respeito às diferenças individuais na forma de enlutar-se.

Não obstante a reflexão ética pautar as ações dos diversos serviços de luto quer estejam situados em clínicas privadas, hospitais ou igrejas, Walter (2000) e Machado e Menezes (2018) apontam que os especialistas do luto estão envolvidos com discursos de significação sobre o sofrimento e isso tem efeitos na vida dos enlutados no sentido de configurar formas sociais e dominantes de como um luto deveria ser vivido. Nesse sentido, os referidos autores destacam como problemática a reprodução de práticas de medicalização, negação e invisibilização dos enlutados e da morte por parte dos especialistas do luto. Sobretudo, porque estes profissionais constroem relacionamentos terapêuticos com vínculos empáticos e favorecedores do apoio social e, consequentemente, o engajamento dos enlutados em práticas de cuidado de si orientadas especialmente pelo modelo de enfrentamento de uma perda que advoga a superação do sofrimento como aspecto fundamental no processo de enlutamento. Os referidos autores também apontam que o que está em questão nesta prática de cuidado de si é a gestão emocional da dor num nível tolerável para não ofuscar o ideal hedonista da sociedade de desempenho.

Por sua vez, Luna e Moré (2013) destacam que na atualidade o luto é reconhecido e vivido pela pessoa no conjunto de relações qualificadas pela pessoa enlutada como de apoio à sua experiência de sofrimento, de modo que a pessoa que perde alguém ou algo significativo não é mera expectadora de relações sociais ou terapêuticas que disciplinarizam ou medicalizam as suas necessidades ou respostas de enlutamento, mas é ativa na gestão compartilhada da sua experiência privada de sofrimento. Sendo assim, neste artigo, entende-se que a experiência de luto é individual e coletiva ao mesmo tempo, pois as circunstâncias e os vínculos que unem as pessoas são únicos, assim como cada perda é única.

Atenta a essa discussão, considero que os serviços de atenção profissional ao luto na atualidade têm o desafio de trabalhar com uma perspectiva construcionista social do luto bem como propor suporte psicológico à pessoa enlutada, sobretudo espaços grupais que visam ao reforço da sociabilidade no luto e ao combate à precarização do compartilhamento do sofrimento diante de uma perda. É nessa direção que realizamos no contexto de um serviço-escola de Psicologia,

Nova Perspectiva Sistêmica, v. 29, n. 68, p. 46-60, dezembro 2020. 
desde 2017, grupos reflexivos e de apoio ao luto (GRAL) com pessoas que procuraram um projeto de extensão universitária implantado em um serviçoescola de uma Universidade Pública.

Sendo assim, neste artigo, tenho como objetivo apresentar uma proposta teóricometodológica para subsidiar a facilitação de grupos reflexivos e de apoio ao luto (GRAL). Para desenvolver este objetivo, abordo, inicialmente, as questões relativas à importância da metodologia grupal como a principal proposta de cuidado ao luto no contexto do projeto de extensão universitária, e na sequência apresento os conceitos principais e as etapas que norteiam a facilitação de um GRAL. Por último, realizo um relato sobre as aplicações da proposta teórico-metodológica do GRAL no serviço-escola de Psicologia.

\section{POR QUE É IMPORTANTE CONVERSARMOS SOBRE O LUTO EM CONTEXTO GRUPAL?}

Desde 2017 desenvolvo o projeto de extensão universitária "Intervenções no luto: acolhimento e suporte psicológico" no serviço-escola de Psicologia de uma Universidade Pública. Este projeto tem como objetivo principal promover o acesso de pessoas enlutadas ao cuidado profissional no luto por meio do acolhimento psicológico individual, bem como pela proposta reflexiva e de apoio ao luto em contexto grupal (Luna, 2020) ${ }^{1}$.

O escopo teórico do projeto é a constatação de que o 'enlutar-se' na atualidade envolve privacidade e individualidade do sofrimento, na precária exposição pública da dor da perda pelos enlutados, no estranhamento da sociedade e inaptidão das pessoas em oferecer apoio social ao luto (Freire, 2005; Koury, 2003). Assim sendo, a realização de intervenções no luto em contexto grupal consiste não apenas em promover um espaço de escuta à pessoa em sofrimento, mas também envolve a possibilidade de oferecer um espaço de compartilhamento de vivências de luto, tornando essa experiência menos individualizada ou privatizada.

O grupo de apoio ao luto - quer seja realizado no âmbito comunitário, instituições de saúde ou em clínicas privadas - consiste em espaços de mútua ajuda, sociabilidade, franqueamento de reações de perda, bem como de aprendizagem de novos comportamentos e ações frente ao luto (Santos, 2017). Por sua vez, há diferentes modalidades de grupos de apoio ao luto a depender do seu objetivo, do público atendido, do local de realização, da metodologia ou, ainda, dos tipos de profissionais envolvidos na organização destes grupos. São exemplos: grupos de mútua ajuda, grupos terapêuticos de luto e os grupos psicoterápicos de luto.

Estes tipos de grupos diferenciam-se pela possibilidade de se realizar intervenções de cunho primário, secundário ou terciário na medida em que existem públicos e objetivos distintos. No que tange aos grupos de mútua ajuda e os grupos terapêuticos de luto, pode-se realizar tanto intervenções primárias quanto secundárias, pois estes tipos de grupos são direcionados a todas as pessoas enlutadas ou, ainda, àquelas

1 Luna, I. J. (2020). A implantação do cuidado profissional ao luto no contexto de uma universidade pública: desafios éticos e metodológicos. In $A$ quem confiar minha tristeza? Faces e perspectivas do cuidado ao luto. Brazil Publishing: Curitiba (no prelo). que apresentam algum fator de risco para complicações no luto. Sendo assim, as intervenções realizadas utilizam recursos comunitários e de psicoeducação para enfatizar a partilha de situações comuns, a diminuição de isolamento social, bem como a obtenção de informações sobre o processo de luto (Rebelo, 2005).

Por sua vez, somente os grupos terapêuticos de luto exigem de seus coordenadores a formação e o domínio de recursos da escuta ativa e aconselhamento no luto, bem como são realizados em contextos específicos, por exemplo, em unidades de cuidados paliativos, ambulatórios gerais etc. Já os grupos psicoterapêuticos 
realizam intervenções terciárias e são direcionados às pessoas que apresentam reações de luto que se encaixam nos critérios clínicos para o luto prolongado. Nesse sentido, propõe-se o tratamento de reações complicadas de luto e são realizados em contextos clínicos e instituições de saúde envolvidas com intervenção terciária no luto (Guillén, Montaño, \& Gordillo, 2015).

Considerando os tipos de grupos de luto, observam-se no âmbito da literatura nacional relatos de experiência sobre a realização de grupos com pais enlutados, pessoas que perderam alguém por suicídio, profissionais de saúde, ou ainda grupos mistos com vários tipos de perdas. Como local de realização dos grupos, destaca-se o contexto hospitalar, como em unidade de terapia intensiva neonatal, ambulatório geral (Pascoal, 2012) e emergência geral (Souza, Moura, \& Corrêa, 2009). Há também grupos de luto realizados em espaços comunitários, como em igrejas (Soares et al., 2020), em unidades básicas de saúde (Souza \& Santos, 2016), em uma organização não governamental (Davel \& Silva, 2014) e clínica privada (Scavancini, Cornejo, \& Cescon, 2019).

Ainda que no contexto brasileiro se encontrem vários tipos de grupos de apoio ao luto, não se identificaram nos estudos apresentados as especificidades teóricas sobre a realização de grupos de luto sob o enfoque dos processos reflexivos, da visão sistêmica, ecológica e complexa. Todavia, foram encontrados trabalhos sobre grupos reflexivos de gênero (Beiras \& Bronz, 2016) e grupos reflexivos com ex-cônjuges diante de conflitos do pós-divórcio (Silva, Oliveira, Soares, \& Rapizo, 2018).

Nesse sentido, para fundamentar teoricamente a intervenção no luto em contexto grupal proposta pelo projeto de extensão citado, busquei subsídios teóricos nos grupos reflexivos de gênero propostos por Beiras e Bronz (2016), na perspectiva construcionista social sobre o luto (Luna, 2013), nos princípios terapêuticos grupais descritos por Yalon e Leszcz (2006) e na postura ética como cuidado ao luto (Gamino, 2009, Tavares \& Rasera, 2013).

Especialmente mediante a capacitação vivencial na metodologia dos grupos reflexivos de gênero, coordenada por professores do Instituto Noos de São Paulo, pude experimentar a posição de participante de um grupo reflexivo de gênero e, a partir desta experiência, compreender que em nossa sociedade há propostas medicalizadoras e disciplinadoras tanto para pessoas viverem suas relações de gênero quanto os seus vários lutos ao longo da vida. Por sua vez, nessa capacitação pude traçar semelhanças entre o trabalho grupal com o luto feito no contexto do projeto de extensão com a metodologia dos grupos reflexivos de gênero. Sendo assim, verifiquei que as semelhanças ocorriam porque ambos os trabalhos grupais possibilitam a construção de diálogos colaborativos e reflexivos em torno do ressignificar a vida e engajar-se consigo próprio e com os outros por meio da desconstrução de discursos limitadores das experiências humanas. Neste artigo, busco ir além das semelhanças apresentadas e na sequência apresento os conceitos principais e procedimentos do GRAL.

\section{CONCEITOS PRINCIPAIS E PROCEDIMENTOS DO GRAL}

Inspirada na metodologia de grupos reflexivos de gênero do Instituto Noos, no que concerne à reflexividade sobre significados que demarcam modos específicos de se viver em sociedade, especialmente quanto às temáticas relações de gênero, sexualidade, violência, luto etc., foi possível desenvolver uma proposta teóricometodológica para subsidiar a facilitação de um GRAL. Para tanto, destaco que os conceitos e princípios que norteiam o GRAL foram adaptados e estão ancorados

Nova Perspectiva Sistêmica, v. 29, n. 68, p. 46-60, dezembro 2020. 
2 Nesta metodologia também estão presentes a perspectiva construcionista social de Kenneth Gergen, a visão pós-estruturalista de Judith Butler, as práticas pedagógicas da Educação Popular de Paulo Freire e a visão sistêmica, ecológica e complexa de Urie Bronfenbrenner, Ludwig Bertalanfy e Edgar Morin (Beiras \& Bronz, 2004, 2016). em alguns conceitos presentes na metodologia dos grupos reflexivos de gênero do Instituto Noos. Ademais, outros conceitos e princípios importantes se somam à proposta aqui apresentada.

A metodologia do grupo reflexivo de gênero ${ }^{2}$ enfatiza as relações grupais e as relações contextuais de cada participante, a narrativa e a produção de processos reflexivos e comunitários, pois cada participante de um grupo traz para o processo relacional sua história prévia, suas posições e compreensão das experiências vividas. No que diz respeito aos estudos de gênero, a visão pós-estruturalista de Judith Butler é um importante fundamento teórico do GRAL na medida em que se problematizam os estereótipos e maneiras unívocas de compreender as vivências e necessidade de luto nos corpos, nos comportamentos, dramatizações e performances a partir de normas binárias de gênero. Assim sendo, as normas de gênero definem modos de entender como natural e correto um modo feminino e/ou masculino de enlutar-se.

Nesse sentido, retomo Doka e Martin (2010), que assinalam as expectativas sociais em se buscar respostas de luto no homem relacionadas às vivências instrumentais a partir de um estilo de enlutamento voltado aos pensamentos e ações; sendo que as vivências intuitivas são geralmente ligadas às mulheres, pois é esperado que estas respondam por meio da externalização das emoções. Considerando essa questão, o GRAL promove reflexões em torno das vivências de luto que não se ligam às normas de gênero binárias, buscando-se construir empaticamente qual o estilo preferencial de 'enlutar-se' de cada pessoa que participa do grupo.

Tal qual nos grupos reflexivos de gênero, no GRAL também são pertinentes as discussões sobre interseccionalidade e os marcadores sociais da diferença como raça, etnia ou orientação sexual, entre outros, e que afetam as vivências individuais e coletivas de luto. Especialmente no que tange ao racismo institucional e à violência estrutural em torno das pessoas negras, Teixeira (2020) assinala que a vulnerabilidade dos pais enlutados em situação violenta é anterior, durante e posterior à morte dos filhos. Sendo assim, a autora destaca as experiências de exclusão e subordinação tanto das relações parentais quanto do luto decorrente da perda de filhos no que diz respeito ao reconhecimento social da importância do vínculo e o sofrimento vivido pelo seu rompimento por pais e mães. Em muitos casos, estes são acusados de não terem protegido os filhos de uma situação de risco, por exemplo, tráfico de drogas, comportamento violento etc.

Sendo assim, promover reflexões grupais sob a ótica dos marcadores sociais da diferença de raça ou classe social significa mapear a reação de não franqueamento que indefectivelmente ocorrerá nas interações grupais e que pode ser observada também na família e na sociedade mais ampla. Esta reação pode significar o fracasso em proporcionar suporte e cuidado mútuo às pessoas em luto, uma vez que estas não são vistas como merecedoras deste luto, pois se presume culpa na perda ocorrida.

Outra situação em que se fracassa na empatia é quando os facilitadores do grupo abusam de autoridade sustentada nos discursos médicos e psicológicos disfarçados numa expertise que presume saber como as diversas pessoas deveriam viver os seus lutos. E, por último, o fracasso da empatia ocorre quando não se alerta os participantes que sanções econômicas e previdenciárias estão previstas às pessoas inseridas no mercado de trabalho, quer seja ele formal ou informal, e isto significa promover reflexões em torno de qual é o preço assumido tacitamente pelo trabalhador quando se ausenta do trabalho por motivo de perda, além dos dias oficialmente destinados para a licença devido ao luto (Attig, 2004).

Estas discussões realizadas até o momento nos alertam que a questão reflexiva em torno de gênero, raça, etnia ou classe social no contexto da facilitação de um GRAL é concomitante à produção da empatia quanto às necessidades pessoais de 
enlutamento e legitimação do luto de cada participante. Nesse sentido, é necessário promover no GRAL a desconstrução da visão de cada participante quanto às regras de luto que conhecem e que dão legitimidade a quem pode estar de luto, como por quanto tempo e por quem as pessoas devem 'enlutar-se'. Nesse sentido, busca-se refletir junto ao grupo se o direito ao luto público é um privilégio para poucos ou se para muitos ele é silenciado ou se torna silencioso (Butler, 2015).

Ao se proporem reflexões em torno do direito ao luto público instauram-se, por um lado, o apoio mútuo e, por outro, o tensionamento diante deste direito. Deste modo, surgem os seguintes questionamentos: o que acontece quando contamos com o outro nossos lutos silenciosos ou silenciados? Que sentidos são produzidos ao se reafirmar as necessidades de enlutamento de todos os presentes no GRAL tendo em vista as questões de gênero, raça, etnia, classe social ou orientação sexual?

Estes questionamentos, por sua vez, nos levam a refletir sobre a postura ética e de cuidado ao luto adotada tanto por parte dos facilitadores quanto dos participantes, sendo que esta postura vai além da ética utilitarista - sobre o que é bom ou ruim no luto - ou ainda os princípios da ética principialista - autonomia, beneficência, não maleficência, justiça e fidelidade. Sendo assim, o que está em questão nas conversações produzidas no grupo é a visão relacional da ética, que enfatiza a construção relacional do suporte à pessoa e os sentidos das suas histórias de perda. Desta forma, se faz uma menção à questão da violência conversacional (Weingarten, 1992), que é citada por Trindade e Rasera (2013) quando os sentidos são impostos, ignorados propositalmente ou mal interpretados em uma interação não colaborativa entre os participantes de uma interação social. No que diz respeito ao GRAL, destacam-se especialmente os sentidos mal interpretados quanto à cultura, valores e crenças de cada um e seus modos de reagir e comunicar suas emoções de luto (Gamino, 2009).

Por meio da postura ética, vista como uma prática responsiva às descrições dos falantes, destaca-se a visão construcionista social da experiência de luto como construção intersubjetiva de histórias e sentidos sobre a perda vivida. Deste modo, o luto é tanto um processo autorreferencial que envolve a reconstrução de significados pessoais e idiossincráticos, tendo em vista que a perda evoca uma crise de significados que estruturam o self, quanto é um processo produzido e negociado recursivamente no âmbito da rede de relacionamentos sociais, por meio de narrativas coletivas sobre como um luto deve ser vivido e externalizado no contexto grupal (Luna \& Moré, 2017). Por sua vez, esta visão destaca a perspectiva da complexidade e da multidimensionalidade da experiência de luto já apontada por Sluzki:

ocorre em todos esses lugares, ou, sendo mais preciso, a experiência propriamente dita, a experiência de perda e de dor, de alegria e amor, de crescer e criar, de viver e evoluir, é única para cada indivíduo-em-contexto, e a conceitualização desses processos é função dos constructos daquele que observa e descreve: nossos modelos são redes ideológicas que procuram, ordenam, organizam e outorgam significado ao que ocorre "aí fora”... e "aí dentro". Essas experiências, independentes de quão intensas sejam, são esfriadas pelo efeito mediatizante da linguagem, que as organiza usando como matriz os múltiplos pressupostos explícitos ou implícitos que nos permitem estabelecer consensos. (Sluzki, 1997, p. 27)

Nova Perspectiva Sistêmica, v. 29, n. 68, p. 46-60, dezembro 2020. 
A partir desta compreensão construcionista social da experiência de luto destacase que ouvir a voz da pessoa enlutada possibilita legitimar o seu direito a 'enlutar-se', bem como dar visibilidade a versões diferentes e alternativas para as mesmas situações e conflitos trazidos pelo enlutado em torno deste direito, agora vistos sob a ótica dos outros participantes do grupo.

Outro importante fundamento teórico do GRAL são os princípios terapêuticos grupais descritos por Yalon e Leszcz (2006), considerando, sobretudo, a possibilidade de se trabalhar com o suporte mútuo entre os participantes por meio dos seguintes aspectos: instilação de esperança frente a um futuro que está sendo reconstruído; a universalidade da situação vivenciada ao perceber experiências e angústias similares que podem ser compartilhadas; o compartilhamento de informações sobre os recursos de enfrentamento no luto; a possibilidade de contribuir com a experiência pessoal para ajudar outra pessoa; reconhecer que às vezes a vida não é justa e discutir questões sobre o sentido da vida e a morte; aprendizagem mútua decorrente da percepção de alguns benefícios decorrentes do enfrentamento de uma perda e o desenvolvimento de relações de confiança; entendimento e aceitação entre si, permitindo, inclusive, que conflitos possam ser expressos.

No que concerne aos princípios metodológicos do GRAL, estes também estão ancorados na metodologia do grupo reflexivo de gênero do Instituto Noos - a saber: constituição do grupo, realização dos encontros reflexivos e avaliação do trabalho. Assim, há aspectos importantes seguidos na realização dos encontros reflexivos, como o acordo de convivência, os disparadores de conversa, a agenda do grupo, a atividade de ligação e o momento de síntese do encontro (Beiras \& Bronz, 2016).

Considerando os fundamentos teóricos e metodológicos apresentados até o momento, um GRAL tem com objetivo geral promover a autoria e o protagonismo do enlutado na vivência de seu luto. E como objetivos específicos destacam-se a construção de empatia e sociabilidade em torno das necessidades de enlutamento no contexto da perda vivida; o compartilhamento de recursos de enfrentamento; a narração de histórias pessoais sobre a perda vivida; e reflexões sobre as narrativas sociais e coletivas produzidas no contexto grupal tendo em vista os marcadores de gênero, raça, etnia, classe social ou orientação sexual.

Foram definidas algumas etapas que norteiam a facilitação do GRAL e que são apresentadas na sequência: (a) a constituição do grupo; (b) o acordo de convivência; (c) a agenda grupal; (d) os disparadores de conversa; (e) as perguntas condicionais e conversacionais; (f) a atividade de ligação; $(\mathrm{g})$ a postura reflexiva; $(\mathrm{h})$ a síntese do encontro; (i) o momento de despedida; (j) a avaliação final; e (k) o cuidado ético.

1. Constituição do grupo: sugere-se realizar entrevistas individuais e de acolhimento com pessoas enlutadas interessadas em participar de um GRAL. Estas entrevistas não têm como foco selecionar ou triar as pessoas, mas tecer um apoio inicial às vivências de cada uma visando à sua compreensão a partir do relato da história pessoal, bem como informar alguns objetivos do grupo para a pessoa identificar o seu interesse neste tipo de trabalho grupal. Sendo assim, após a realização das entrevistas, sugere-se que um GRAL tenha início com um número máximo de dez ou o mínimo de cinco pessoas.

2. Acordo de convivência: este dispositivo norteia todos os encontros do GRAL, mas é construído nos primeiros encontros. Significa definir alguns acordos de convivência coletiva que servem para mediar o comportamento de todos os participantes, por exemplo, as formas de comunicação em caso de falta, atrasos e se novos participantes poderão entrar no grupo após o seu início. Sugere-se também definir neste acordo o número de encontros e o intervalo 
entre eles, sendo que todos os acordos feitos poderão constar em um documento escrito que poderá ser entregue aos participantes em encontros subsequentes. Recomenda-se o número mínimo de oito e máximo de dez encontros, com intervalos semanais ou quinzenais a ser acordado entre os participantes de cada GRAL.

3. Agenda grupal: de forma semelhante ao acordo de convivência, estimula-se no início de cada encontro que cada participante compartilhe a sua história pessoal de perda considerando as suas necessidades de enlutamento. A partir do relato dessas histórias, sugere-se construir junto com os participantes uma lista de temas possíveis que poderão ser trabalhados ao longo dos encontros reflexivos.

4. Disparadores de conversas: trata-se dos temas selecionados pelos participantes considerando a agenda grupal e que são abordados em cada encontro. Além disso, os facilitadores do grupo também podem levar para os encontros reflexivos alguns recursos auxiliares para disparar conversas, por exemplo, folder sobre reações de luto, trechos de filmes, músicas, poesias etc.

5. Perguntas condicionais e conversacionais: são perguntas usadas a fim de se obter informações sobre a história pessoal de cada participante em relação ao tema que foi escolhido da agenda grupal (perguntas condicionais) bem como quando se busca promover a circulação de reflexões oriundas dos próprios participantes (perguntas conversacionais). Nessa direção, também se destaca a importância do uso da pergunta conversacional "como se", que tem como objetivo promover a construção de narrativas alternativas a fim de revisar o fluxo de acontecimentos que culminou com a morte do seu ente querido, bem como diminuir o sentimento de impotência ou ainda de responsabilização pela morte ocorrida. Como exemplo de pergunta 'como se', cito a seguinte questão que pode ser realizada aos participante de um GRAL: na sua visão, se você pudesse voltar no tempo, o que poderia ter sido feito por você e que alteraria o curso de acontecimentos que culminou com a morte do seu ente querido? (Vasconcellos, 2010).

6. Atividade de ligação: trata-se de uma atividade que pode ser realizada pelos participantes no intervalo dos encontros do grupo. Para tanto, sugere-se a confecção de um diário de viagem composto por algumas atividades como ouvir músicas, ver filmes, identificar objetos de apego ou mensagens que lembrem a pessoa que morreu. Além disso, essa atividade pode ser vista como um disparador de conversa para dar início aos encontros reflexivos, principalmente quando esta produção se referir a alguma data que lembra a pessoa que morreu ou marcar um ritual familiar e de passagem do tempo, por exemplo, o primeiro ano da perda.

7. Postura reflexiva: envolve auto-observação dos facilitadores quanto às narrativas dos participantes que estão circulando no grupo e como isso os está impactando. Manter a postura reflexiva significa que os facilitadores podem compartilhar suas impressões e devolvê-las ao grupo em forma de novas perguntas conversacionais ou condicionais. Nesse sentido, destaca-se a importância de duas pessoas para facilitar o grupo, tendo em vista o que representa fazer a auto-observação para cada facilitador e como eles podem devolver singularmente ao grupo o que pensaram e refletiram a partir da auto-observação realizada.

Nova Perspectiva Sistêmica, v. 29, n. 68, p. 46-60, dezembro 2020. 
8. Síntese do encontro: este momento tem duas etapas. A primeira é denominada de "hora do chá" e visa à promoção de um descanso, descontração e preparação dos participantes para se envolver com a segunda etapa. Nesse sentido, na "hora do chá", convidam-se os participantes a formar espontaneamente pequenos subgrupos e continuar as interações verbais ou ainda apenas a se servir de chá, café, água ou chocolate ou ir ao toalete. Nesse momento, os facilitadores do GRAL também atendem à sua necessidade de descanso e buscam atividades para relaxar. Sugere-se que a duração da hora do chá seja de 15 a 30 minutos e após esse período os facilitadores podem inserir algumas perguntas para realizar a segunda etapa da síntese do encontro, por exemplo: o que você fez e/ou escutou hoje que foi significativo para o seu processo de luto? O que o grupo está levando deste encontro reflexivo? As respostas podem ser registradas numa folha de cartolina por meio das palavras principais que foram designadas pelos participantes para nomear o que foi mais significativo no encontro reflexivo.

9. Momento da despedida: trata-se do encerramento do encontro grupal e pode ocorrer mediante as sugestões dos participantes de cada encontro grupal. Sendo assim, uma pergunta importante é: como gostaria de encerrar o encontro? Antes do encerramento de cada encontro grupal também é reforçada a importância de se realizar uma atividade de ligação no intervalo entre os encontros.

10. Avaliação final do GRAL: esta atividade consiste numa avaliação livre e verbal de como os participantes vivenciaram as atividades do GRAL, e é feita no último encontro do grupo. Sendo assim, pode-se solicitar que os participantes relatem algo que registraram no diário de viagem ou ainda que compartilhem como percebem o seu processo de luto antes de participar do grupo e no momento atual. Neste momento, os facilitadores também podem retomar os principais pontos reflexivos que surgiram nos encontros, bem como os aspectos que foram observados no processo de luto de cada participante.

11. Cuidado ético no GRAL: a questão da postura ética deve estar presente durante todo o contexto de constituição, facilitação e avaliação do GRAL e está pautada nas seguintes perguntas: Quem é a pessoa que procura o grupo? Quais as situações geradoras de violência conversacional? Quais são os limites do grupo em termos de suporte psicológico para as demandas de luto complicado? Como a postura ética é assumida pelos facilitadores na prática do GRAL? Como garantir que várias vozes serão ouvidas durante o processo? Estas perguntas assinalam a possibilidade de identificar os "pontos cegos" em relação às pessoas e processos narrativos que podem ser desconsiderados pelos facilitadores do grupo, por exemplo, a discussão sobre luto na perspectiva de gênero, raça, etnia, idade, classe social ou orientação sexual. Destacase também a importância de se observar os requisitos éticos demandados à profissão de psicólogo (Código de Ética Profissional do Psicólogo, 2005), como as práticas de sigilo e privacidade. Na sequência, apresenta-se um relato de experiência quanto à realização do GRAL considerando a aplicação dos conceitos e princípios destacados até o momento. 
APLICAÇ̃̃ES DA PROPOSTA DO GRAL E OS SEUS DESAFIOS: UM RELATO DE EXPERIÊNCIA

No contexto do projeto de extensão implantado em um serviço-escola de Psicologia de uma Universidade Pública foram realizados cinco GRAL. Participaram efetivamente de cada grupo em média seis pessoas, sendo que no total dos cinco grupos quarenta e três pessoas frequentaram o GRAL. Na sua maioria mulheres (35), com perdas significativas, como o pai ou a mãe, o cônjuge, um filho(a) ou irmão em circunstâncias adversas como suicídio, perda de filho, doença avançada, perda gestacional ou infarto. Há também participantes que relataram a ocorrência da perda de mais de um membro da família num curto espaço de tempo, além de relações muito significativas, como o animal de estimação, entre outras perdas simbólicas. O tempo de perda antes de procurar o grupo variou - com perdas de menos de um ano, que foram sua maioria, e perdas entre um e cinco anos. Porém, há participantes com perdas acima de dez anos.

Os grupos aconteceram em 2017, em 2018 e em 2019, tendo sido realizados oito encontros quinzenais em cada semestre letivo. O tempo de cada encontro foi de 2 horas, sendo que a facilitação do grupo ocorreu sob responsabilidade da professora e coordenadora do projeto e um extensionista.

Observaram-se, ao longo dos grupos realizados, vários desafios em relação à construção de um espaço de sociabilidade e percepção empática das necessidades de enlutamento entre os participantes e os facilitadores do grupo, considerando a condução dos encontros reflexivos a partir dos princípios e etapas estabelecidas.

Nesse sentido, o desafio na produção de apoio mútuo (sociabilidade) e comunicação empática foi observado sempre nos inícios dos encontros, quando ocorria o relato da história de perda pelos participantes. A partir desses relatos eram negociados os temas a serem explorados durante o encontro reflexivo e para o qual convergiam os relatos sobre as singularidades dos participantes do grupo, considerando quem era a pessoa que morreu e quem era o enlutado, seu sexo, gênero, idade, classe social ou raça e os grupos frequentados pelos participantes, escola, família, amigos, religião etc. no que tange ao suporte percebido para o seu luto.

No que diz respeito aos disparadores de conversas/temas, são exemplos: as dúvidas quanto à conduta médica diante do tratamento de saúde do seu ente querido; reações de outras pessoas e que foram consideradas negativas em termos de suporte social dado no luto; dificuldade no manejo de emoções difíceis como culpa e raiva; várias perdas secundárias vividas no luto; necessidade de perdoar a pessoa que morreu e saber se foi perdoado por ela; preconceitos sobre viver o luto em contextos familiares e sociais; questões pendentes com a pessoa que morreu; estados emocionais como raiva, culpa, ansiedade, medo, tristeza, saudade, solidão e isolamento social; espaço para chorar e ter autorização para estar de luto; dificuldade de comunicação e relacionamento familiar após a perda, construção de novos projetos de vida, autocuidado no luto; experiência de ter cuidado da pessoa que faleceu, datas comemorativas; rituais de despedidas; mudanças e retomada da rotina; uso de crenças religiosas para compreensão dos significados da vida e da morte.

Outro desafio na facilitação do GRAL foi a produção da postura reflexiva diante das conversações sobre as necessidades de enlutamento, por vezes diferentes em um único encontro grupal. Enquanto alguns participantes buscavam respostas para o ocorrido com o familiar, outros relatavam o relacionamento simbólico mantido com o ente querido que faleceu ou ainda destacavam o que significava a retomada da vida diária sem esta pessoa etc. Outro eixo de conversações também se referia aos recursos de significação do sofrimento ou da morte, como o uso de crenças

Nova Perspectiva Sistêmica, v. 29, n. 68, p. 46-60, dezembro 2020. 
religiosas específicas, sendo que alguns participantes, às vezes, buscavam influenciar as demais pessoas do grupo sobre o valor das suas crenças. Além disso, vários participantes delineavam narrativas sobre o tempo cronológico do luto, associação entre luto e doença mental ou ainda luto e fracasso existencial.

Considerando estas narrativas, o desafio dos facilitadores do grupo na realização da síntese dos encontros foi sustentar uma postura reflexiva em torno da diversidade de recursos sociais e culturais de cada participante ao lidar com sua perda e que foram compartilhados ao longo dos encontros. Por exemplo, formas específicas de buscar conforto emocional na dor por meio de orações, exercício físico, música, poesias, pedidos de perdão, cartas psicografadas ou rituais personalizados de luto, bem como pelas decisões tomadas pelos participantes durante a participação no grupo, como voltar a trabalhar, fazer uma viagem etc.

Foi fundamental no GRAL sustentar as conversações grupais em torno dos sentidos do cuidado ao luto de cada um para que os participantes pudessem reconhecer, dentro de várias possibilidades de cuidado, aquelas que lhe são específicas e úteis para a subjetivação da sua perda e o sentido de continuidade da sua biografia pessoal. Este pode ser visto no momento da avaliação final do GRAL, quando conversas foram realizadas sobre todo o processo grupal e cuidado ao luto gerado pelo protagonismo e autoria de cada participante tendo em vista as histórias e sentidos da perda compartilhados.

No que se refere às avaliações finais realizadas pelos participantes, observou-se o compartilhamento de percepções considerando as emoções, dúvidas, estigmas e vulnerabilidades anteriores à perda e as vivências obtidas durante o trabalho grupal. Destacam-se os relatos de altruísmo e universalidade, quando os participantes perceberam que ajudaram outros do grupo, bem como puderam falar, ser escutados e perceber que aquilo que sentem e vivem faz parte do seu processo de luto. Os participantes também relataram a diminuição de sentimentos de impotência e responsabilização pelo ocorrido com o seu ente querido, bem como o aumento de esperança e recuperação de alguns propósitos de vida.

Considerando os desafios relatados na facilitação de cinco grupos de luto sob o enfoque dos princípios teóricos e metodológicos do GRAL, destaco a citação que utilizei como forma de encerramento dos grupos realizados:

Somos vozes num coro que transforma a vida vivida em vida narrada e depois devolve à narração à vida, não para refletir a vida, e sim, mais corretamente, para agregar-lhe algo; não uma cópia, mas uma nova dimensão; para agregar com cada novela algo novo, algo mais, à vida. (Carlos Fuentes citado por Anderson \& Goolishiam, 2007, p. 191)

A partir desta citação busco dar importância à potência da voz individual e coletiva presente nas histórias e sentidos da perda que foram compartilhadas, ou seja, o processo autorreferencial de luto como uma experiência de protagonismo e autoria que convida a pessoa em luto a recriar novas narrativas e novas maneiras de viver a sua vida no coletivo. 
Neste artigo apresentei uma proposta teórico-metodológica para subsidiar a facilitação de grupos reflexivos e de apoio ao luto e que foi ancorada na realização de intervenções no contexto de um serviço-escola de Psicologia, bem como na adaptação dos dispositivos da metodologia dos grupos reflexivos de gênero do Instituto Noos, e que somados à visão construcionista social do luto, à postura ética de cuidado ao luto e aos princípios terapêuticos grupais, possibilitaram a construção dos objetivos do GRAL e as estratégias e etapas para sua realização.

Destaca-se como um ponto forte na facilitação do grupo quando as perguntas condicionais são também realizadas de um participante para outro, ou seja, quando estes buscam mutuamente conhecer os aspectos singulares de cada história contada a partir das ressonâncias produzidas pelas conversações grupais, sendo que, concomitante à realização de perguntas condicionais, também ocorreram perguntas conversacionais e que significaram que cada participante devolveu ao grupo o que ouviu e pensou com os demais. Nesse sentido, a circulação de perguntas condicionais e conversacionais entre os participantes do grupo é um importante norteador de que o GRAL pode ser visto como um grupo terapêutico e, ao mesmo tempo, um grupo com caráter de mútua ajuda, pois favorece comportamentos e aprendizagens a partir da partilha e troca social no âmbito comunitário.

Uma das questões a ser destacada é quanto ao exercício da auto-observação, por parte dos facilitadores, quando diferentes narrativas circulam no grupo e há o embate entre discursos religiosos, científicos e políticos sobre as causas da morte de um ente querido. Todavia, ao se retomar a auto-observação no momento da supervisão, realizada com os extensionistas do projeto de extensão, era possível compreender os pontos cegos relativos a essas narrativas durante os encontros e como estes afetaram os facilitadores na manutenção da postura reflexiva.

Outra dificuldade encontrada nos grupos foi a intermitência de participação das pessoas ao longo dos encontros e que provavelmente estava ligada ao fracasso da empatia ocorrida no contexto grupal, principalmente em situações específicas, como diante da perda de uma animal de estimação, lutos específicos, como o suicídio de um filho, invisibilidade de mulheres lésbicas viúvas, homens com história de abuso de drogas, afastamento e perda dos filhos, mães com perda gestacional, lutos cronificados depois de um longo tempo de luto ou ainda homens enlutados pela morte de seus filhos e que compareciam nos encontros grupais quando as esposas os acompanhavam.

Nesse sentido, um dos aprendizados na composição e facilitação de um GRAL foi compreender que haverá tensionamentos no grupo quando, nos relatos dos participantes, ressoam os tabus da morte presentes na sociedade. Contudo, o maior ganho de um trabalho grupal reflexivo é que muitas necessidades de enlutamento podem ser aceitas e compreendidas quando se narra e se produz com o outro as histórias que foram silenciosas ou silenciadas em outros contextos relacionais e sociais.

Deste modo, ao se trabalhar com grupos de luto, é importante considerar que enquanto algumas pessoas têm o privilégio de contar e viver o seu luto, outras não têm o direito a contar publicamente as suas histórias de perda, como nos ensina Judith Butler. Como disse uma mãe em um dos encontros:

nem sempre eu digo que o meu filho morreu assassinado, às vezes eu digo que ele morreu de bala perdida, pois nem sempre quero ouvir as pessoas perguntarem se o meu filho era drogado, vendia drogas ou então me consolarem que esse era o destino dele.

Nova Perspectiva Sistêmica, v. 29, n. 68, p. 46-60, dezembro 2020. 
Concluo este artigo assinalando que, ainda que o luto seja uma vivência universal, a maneira de expressá-lo é variada, pois perpassa as regras de luto com as quais se legitimam as pessoas quem têm direito ao luto público e as pessoas que não têm esse direito. Deste modo, um grupo reflexivo e de apoio a luto pode ser um importante aliado na construção de reflexões e apoio às pessoas enlutadas em torno das regras e o direito ao luto público em qualquer circunstância de morte, considerando quem morreu, quem é o enlutado, onde ele vive e qual é a sua cultura. Destaco, outrossim, que isso envolve desconstruir os discursos limitadores das experiências humanas no que tange aos marcadores sociais da diferença como raça, etnia, classe social ou orientação sexual.

\section{REFERÊNCIAS}

Anderson, H. \& Goolishian, H. (1997). Narrativa e self: alguns dilemas pós-modernos da psicoterapia. In D. F. Schnitman (Org.), Novos Paradigmas, Cultura e Subjetividade (pp. 191-203). Porto Alegre: Artmed/Bookman.

Attig, T. (2004). Disenfranchised grief revisited: discounting hope and love. Journal of Death and Dying, 49(3), 197-215.

Beiras, A.s \& Bronz, A. (2004). Conversas homem a homem: Grupo Reflexivo de Gênero. Metodologia. Rio de Janeiro: Instituto Noos.

Beiras, A. \& Bronz, A. (2016). Metodologia de grupos reflexivos de gênero. Rio de Janeiro: Instituto Noos. Recuperado de https://margens.paginas.ufsc.br/ files/2020/06/Metodologia-Noos__PDF-final.pdf

Butler, J. (2015). Quadros de guerra: quando a vida é passível de luto? Rio de Janeiro: Record.

Conselho Federal de Psicologia - CFP. (2005). Código de Ética Profissional do Psicólogo. Brasília, DF: Autor. http://site.cfp.org.br/wp-content/uploads/2012/07/codigode-etica-psicologia.pdf

Davel, A. P. C., \& Silva, D. R. (2014). O processo de luto no contexto do API-ES: aproximando as narrativas. Pensando Famílias, 18(1), 107-123. Recuperado de http://pepsic.bvsalud.org/scielo.php?script=sci_arttext\&pid=S1679-494X201400 0100010\&lng=pt\&tlng $=$ pt.

Doka, K. E. \& Martin, T. (2010). Grieving beyond gender: understanding the way men and women mourn. New York: Routledge.

Freire, M. C. B. (2005). O som do silêncio: isolamento e sociabilidade no trabalho de luto. Natal: EDUFRN.

Gamino, L. A. (2009). Ethical decision making: five P model. In Ethical Practice in Grief Counseling (pp. 7-29). New York: Springer Publishing Company.

Guillén, E. G.y Montaño, M. J. G.y \& Gordillo, M. D. G. (2015). El grupo me ayudó a no estancarme. El avance en el proceso de duelo. International Journal of Developmental and Educational Psychology INFAD, 2(1), 469-476, DOI: 10.17060/ ijodaep.2015.n1.v2.126.

Kouryy, M. G. P. (2003). Sociologia da Emoção: o Brasil urbano sob a ótica do luto. Petrópolis, RJ: Vozes.

Luna, I. J. \& Moré, C. O. O. (2013). O modo de enlutamento na contemporaneidade e o aporte do construcionismo social. Nova Perspectiva Sistêmica, 46, 20-35.

Luna, I. J. \& Moré, C. O. O. (2017). Reconstrução do significado no luto. Revista M. Estudos sobre a morte, os mortos e o morrer, 2(3), 152-172. http://dx.doi. org/10.9789/2525-3050.2017.v2i3.p.\%20152-172 
Machado, R. \& Menezes, R. A. (2018). Gestão emocional do luto. Revista Ciências da Sociedade (RCS), 2(3), 65-94. doi.org/10.30810/rcs.v2i3.622

Pascoal, M. (2012). Trabalho em grupo com enlutados. Psicologia em Estudo, 17(4), 725-729. DOI: https://doi.org/10.1590/S1413-73722012000400019.

Rebelo, J. E. (2005). Importância da entreajuda no apoio a pais em luto. Análise Psicológica, 23(4), 373-380.

Santos, G. C. B. F. (2017). Intervenção do profissional de saúde mental em situações de perda e luto no Brasil. Revista M. estudos sobre a morte, os mortos e o morrer, 2 (3), 116-137. http://seer.unirio.br/index.php/revistam/article/view/8152.

Scavancini, K., Cornejo, E. R., \& Cescon, L. F. (2019). Grupo de apoio para enlutados por suicídio. Revista M. Revista M. estudos sobre a morte, os mortos e o morrer, 4(7), 201-2014. http://www.seer.unirio.br/index.php/revistam/article/view/8981

Silva, L. O., Oliveira, L. R. R. C., Soares, L. C. E. C., \& Rapizo, R. L. (2018). Diálogos com pais e mães separados: grupos reflexivos no sistema de justiça. Nova Perspectiva Sistêmica, 27(62), 88-108. https://dx.doi.org/10.21452/2594-43632018v27n62a06

Sluzki, C. E. (1997). A rede social na prática sistêmica: alternativas terapêuticas. São Paulo: Casa do Psicólogo.

Souza, A. M., Moura, D. S. C., \& Corrêa, V. A. C. (2009). Implicações do pronto atendimento psicológico de emergência aos que vivenciam perdas significativas. Psicologia Ciência e Profissão, 29(3), 534-543. DOI: https://doi.org/10.1590/ S1414-98932009000300008.

Soares, L. G, Kuchla, E., Mazza, V. A., Soares, L. G.s Ferraz, M. I. R., \& Mattei, A. P. (2020). Mães de anjos: (re)vivenciando a morte do filho como estratégia de enfrentamento. Escola Anna Nery, 24(1), 1-9. https://doi. org/10.1590/2177-9465-ean-2019-0030

Souza, A. S. S. S. \& SantoS, F. S. (2015). Histórias de morte e luto: um estudo socioantropológico da vivência da morte em um grupo operativo no CRAS. Revista de Psicologia, 6(2), 50-58. http://www.periodicos.ufc.br/psicologiaufc/ article/view/2581

Teixeira, T. (2020). Luto paterno: revisão integrativa da literatura cerca do pai que perdeu seu filho por causa externa. Dissertação de Mestrado, Programa de Pós-graduação em Psicologia Clínica, Pontifícia Universidade Católica de São Paulo, SP.

Trindade, F. M. O. \& Rasera, E. F. (2012). Considerações Sobre uma Ética Relacional. Psico, 44(1), 130-138.

Vasconcellos, M. J. (2010). O uso de perguntas como recurso para desencadear mudanças sistêmicas: articulando os múltiplos rótulos utilizados para diferentes formas de perguntar. In J. G. Aun \& M. J. Vasconcellos, \& S. V. Coelho (Eds.), Desenvolvimento de práticas com a metodologia de atendimento sistêmico. (186209). Belo Horizonte: Ophicina de Arte \& Prosa.

Walter, T. (2000). Grief narratives: the role of medicine in the policing of grief. Antropology \& Medicine, 7(1), 97-114.

Weingarten, K. (1992). A consideration of intimate and non-intimate interactions in therapy. Family Process, 31, 45-59. https://doi. org/10.1111/j.1545-5300.1992.00045.x

Yalom, I. D. \& Leszcz, M. (2007). Psicoterapia de grupo: teoria e prática. Porto Alegre: Artmed. 


\section{IVÂNIA JANN LUNA}

É professora do Departamento de Psicologia da Universidade Federal de Santa Catarina do Mestrado Profissional em Saúde Mental do Departamento de Saúde Pública. Psicóloga com formação em Terapia Relacional Sistêmica (Instituto Movimento Sistêmico/SC); mestre em Psicologia Clínica (PUC/SP), doutora em Psicologia (UFSC) e pós-doutora em Psicologia Clínica (PUC/SP). Atua como supervisora de estágios em Psicologia sob o enfoque da perspectiva sistêmica e do construcionismo social. É fundadora e coordena o Laboratório de Processos Clínicos e Psicossociais no luto (LAPPSILu) da UFSC.

https://orcid.org/0000-0003-3095-5134

E-mail: ivaniajannluna@gmail.com 